\title{
Comparison of Premixed with Sequential Administration of Intrathecal Morphine and Hyperbaric Bupivacaine for Lower Segment Caesarean Section
}

\author{
Jahanara', Harish Singh Koshyari', Veena Asthana', Ruchira Nautiyal ${ }^{2}$ \\ ${ }^{1}$ Department of Anaesthesiology, Himalayan Institute of Medical Sciences, SRHU, Dehradun, Uttarakahand, India, ${ }^{2}$ Department of Obstetrics and \\ Gynaecology, Himalayan Institute of Medical Sciences, SRHU Dehradun, Uttarakahand, India.
}

\section{Abstract}

Background: Adequate pain relief is considered as a basic human right .In obstetrics patients, using low dose opioids (Morphine, Fentanyl, sufentanil) in neuraxial blockade is effective method for anaesthesia and postoperative analgesia in LSCS and nearly no danger to parturient or unborn. Subjects and Methods: Keeping in mind the difference in the baricties of commonly used hyperbaric bupivacaine and morphine, we conducted a single blind randomized controlled trial on 156 full term parturient scheduled for elective and emergency LSCS under SAB and on the technique of intrathecal administration of drug parturients were divided into 3 groups. GROUP 1 ( $\mathrm{n}=52$ ) - Hyperbaric bupivacaine $(0.5 \%) 9 \mathrm{mg}(1.8 \mathrm{ml})+$ morphine $200 \mathrm{mcg}(0.2 \mathrm{ml})$ as a mixture GROUP $2(\mathrm{n}=52)$-Hyperbaric bupivacaine $(0.5 \%) 9 \mathrm{mg}(1.8 \mathrm{ml})+\mathrm{Morphine}$ 200mcg (0.2ml) administered after bupivacaine GROUP 3 ( $\mathrm{n}=52)$-Hyperbaric bupivacaine $(0.5 \%) 9 \mathrm{mg}(1.8 \mathrm{ml})+\mathrm{Morphine} 200 \mathrm{mcg}(0.2 \mathrm{ml})$ administered before bupivacaine. We observed for block characteristics, maternal hemodynamics and neonatal outcome. Results: In our study, duration of analgesia was clinically prolonged in all the groups. The block characteristics were comparable between the groups. These beneficial effects were not accompanied by any major hemodynamic instability or adverse effects and no untoward effect on the newborn. Conclusion: Premixed and sequential administration of IT morphine with hyperbaric bupivacaine were comparable in terms of quality of subarachnoid block maternal hemodynamic and neonatal outcome.

Keywords: Lower segment cesarean section, Sequential intrathecal injection, Morphine, Hyperbaric bupivacaine, Spinal anesthesia.

Corresponding Author: Dr. Harish Singh Koshyari, Department of Anaesthesiology, Himalayan Institute of Medical Sciences, SRHU, Dehradun, Uttarakahand, India.

Email: harish834@gmail.com

Received: May 2020

Accepted: June 2020

\section{Introduction}

Spinal anaesthesia has long been used for LSCS, but there has always been an area of interest to search for method to provide better quality of interaoprative anaesthesia and prolongation of postoperative analgesia. ${ }^{[1]}$ Opioids (e.g.morphine) have synergistic effect with local anesthetic when given intrathecally ${ }^{[2,3]}$ by reducing visceral pain, thereby improving the the block quality, ${ }^{[4]}$ while also causing reduction of LA dosages and maintaining stable hemodynamic parameters. ${ }^{[1]}$ It enhances postoperatively analgesia period. ${ }^{[5,6]}$

Routine practice of mixing opioid to local anaesthetic is although easy but may alter the baricity and hence effecting spread in CSF .We planned this study with the hypothesis that simply depositing Local anaesthetic and opioid using separate syringes may reduce these changes and influence spread.we compared the effect of premixed (Hyperbaric bupivacaine and Morphine) and sequential administration of additive (Morphine) before and after hyperbaric bupivacaine on block characterstics and maternal and fetal outcome.

\section{Subjects and Methods}

This single-blinded randomized controlled study was conducted in the Department of Anaesthesiology intensive Care and Pain Management Himalayan Institute medical science Swami Rama Nagar, Dehradun after approval from ethics committee over a period of 12 month. Patient selection was done after taking written informed consent from them. 156 healthy, full term, non laboring parturient, ASA I or ASA II with singleton, uncomplicated pregnancy planned for both elective and emergency LSCS under SAB were involved in the study. Parturients with complicated pregnancies like Multiple pregnancy, Pregnancy with bleeding disorders, spinal deformity, any other contraindication to spinal anesthesia block, Pregnancy with acute fetal distress, Intrauterine deaths or known fetal anomaly, Severe PIH (Pregnancy Induced Hypertension), systemic diseases like (renal, cardiac, or liver), those with an 
allergy to the drug or patients who provided refusal against regional anesthesia administration were excluded.

Parturient posted for elective LSCS were kept fasted orally for $8-10 \mathrm{hrs}$ and emergency cases were taken up irrespective of fasting status. Intravenous access was established with a wide bore cannula (16G or $18 \mathrm{G}$ ) either in the ward for elective cases or in the emergency department for the emergency cases. All the parturient were premeditated with injection Ranitidine 50mg and injection Metaclopramide $10 \mathrm{mg}$ given intravenously 30 minutes prior to surgery.

For our study the two drugs used, were kept same throughout then study period to avoid manufacturer's difference. Hyperbaric bupivacaine was used HEAVY ANAWIN (Neon laboratories) and morphine (MORPHITROY) was used. In the operating room all essential multipara monitor (Drager vista 120) were attached. Baseline percentage of oxygen saturation of hemoglobin (SPO2), systolic blood pressure (SBP), diastolic blood pressure (DBP), mean arterial blood pressure (MABP) and heart rate $(\mathrm{HR})$ were noted. Preloading was done with $20 \mathrm{ml} / \mathrm{kg}$ ringer's solution intravenously (I.V), 15-20 minutes before giving the spinal block. Foley's catheterization was done before administration of subarachnoid block (SAB). After thorough hand washing and wearing personal protective equipment's, patient's back was cleaned and draped under all aseptic precautions as per the hospital infection control protocol. With patient in sitting position, a local block with $2 \%$ lignocaine was given at the selected intervertebral space L3-L4. A 26G Quincke's needle was inserted and after confirmation of CSF flow, the anesthetic drug was administered.

The parturients were randamised into three groups and each group has 52 patients. The Group $1(\mathrm{n}=52)$ received intrathecal hyperbaric bupivacaine $(0.5 \%) 9 \mathrm{mg}(1.8 \mathrm{ml})+$ morphine $200 \mathrm{mcg}(0.2 \mathrm{ml})$ as a mixture ,GROUP $2(\mathrm{n}=52)$ received intrathecal hyperbaric bupivacaine $(0.5 \%) 9 \mathrm{mg}$ $(1.8 \mathrm{~m} 1)+$ Morphine $200 \mathrm{mcg}(0.2 \mathrm{~m} 1)$ administered after hyperbaric bupivacaine and GROUP $3(\mathrm{n}=52)$ received intrathecal hyperbaric bupivacaine $(0.5 \%) 9 \mathrm{mg}(1.8 \mathrm{~m} 1)+$ Morphine $200 \mathrm{mcg}(0.2 \mathrm{ml})$ administered before hyperbaric bupivacaine by using seperate syringe via G26 Quincke's needle.

After the spinal block was given, the parturient were laid supine position with $15^{\circ}-20^{\circ}$ left tilt. Oxygen $(5 \mathrm{~L} / \mathrm{min})$ by simple facemask was administered throughout the surgery and was discontinued post-operatively (unless otherwise indicated as per patient requirement). Fluid therapy was continued with ringer's solution $10 \mathrm{ml} / \mathrm{kg} / \mathrm{hr}$. Anesthesiologist, who was not knowing the group allocation, assessed the spinal block and other physiological parameters. Heart rate, $\mathrm{SBP}, \mathrm{DBP}, \mathrm{SpO}_{2}$ were monitored at every 2 minutes (min) for the first 20min and then every $5 \mathrm{~min}$ subsequently till $75 \mathrm{~min}$. Onset of sensory block was noted which was evaluated by the patient providing information regarding feeling of warmth, limb heaviness, or sense of tingling and objectively established by reduced Visual Analogue Scale (VAS) scores of 5 and less to pinprick at level of calf. After the T6 level reached, the surgery began after intimation to surgeon for the initiation of procedure. Demographic data, such as age, weight $(\mathrm{kg})$, height $(\mathrm{cm})$, and the duration of the operation were recorded. After onset of hypotension (NIBP $\leq 100 / 60$ ), anesthetist was allowed managing the patient by giving IV crystalloids $(200 \mathrm{ml})$ fluids and (IV) ephedrine (5-10 mg) . Bradycardia (HR <50 beats/minute) Injection Atropine $20 \mathrm{mcg} / \mathrm{kg}$ iv. was administered for the same \& other introperative adverse events were noted and managed accordingly.

The duration of onset of sensory block, time to maximal sensory block height at (T6) the dermatomal level and regression time to T10 were recorded. Assessment of Motor blockade was done by the Bromage scale, in which 0indicated that patient, is able to lift an extended leg, 1- not able to lift the extended leg , 2- not able to flex, the knee joint and 3- inability in flexing the ankle joint. Onset of motor block was defined as time to attain Bromage scale 3 from subarachnoid block administration. While total duration of motor blockade was defined as the onset of motor block to complete recovery was recorded. ${ }^{[7]}$ Newborn's APGAR scores were recorded by a pediatrician at $1,5,10$ minutes. ${ }^{[8]}$ The spinal anesthesia-related intraoperative and postoperative complications, such as hypotension, bradycardia, nausea vomiting, pruritis, sedation and respiratory depression was noted and recorded. The total time of postoperative analgesia was recorded as the time interval between the $\mathrm{SAB}$ and the first intimation by the patient for rescue analgesia. By Visual analogue scale (VAS) score, assessed the degree of postoperative pain. VAS scores described the postoperative pain intensity as having no pain ( 0 to $4 \mathrm{~mm}$ ), having mild pain ( 5 to $44 \mathrm{~mm}$ ), having moderate pain $(45$ to $74 \mathrm{~mm})$, and having severe pain $(75$ to100 $\mathrm{mm}$ ) (9). Rescue analgesia was given in form of 1 gram of paracetamol (IV) was given for analgesia. Postoperatively any incidence of bradycardia, hypotension PONV, prolonged sedation reported by the allocated postoperative care unit staff was managed accordingly. On the first post-operative day, parturient were also evaluated for post dural puncture headache, backache and examined for any neurological deficit.

Aim of our study was to determine block chracterstics (sensory block onset time, motor blockade onset time, highest level of sensory blockade, motor blockde duration interval), hemodynamic status and neonatal outcome.

\section{Sample Size}

The previous correlated studies were taken into account to calculate the sample size. Power analysis recommended that sample size of 52 patients each group were required to attain a power of $80 \%$ and a level significance of 0.05 to be able to identify a difference between the groups.

\section{Statistical Analysis}

Statistical analysis was done using Microsoft Excel and version 22 of SPSS. Continuous variables are noted as mean $\pm \mathrm{SD}$, and categorical variables are presented as percentage and numbers . Normally distributed continuous variables were compared using ANOVA. If the F value was significant and variance was homogenous,for individual group differences Tukey multiple comparision test was used otherwise, Tamhane's T2 test was used. Chi square test was applied for categorical variables analysis. 


\section{Flow diagram showing Sequential assessment of parturient enrolled in study}

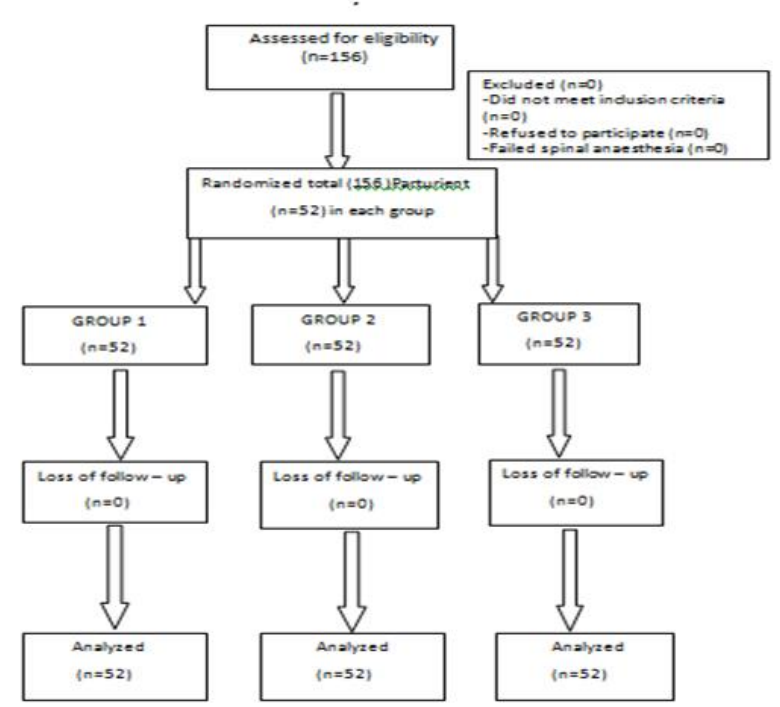

Figure 1: Consort

Flow chart of Parturients.156 parturient underwent screening for eligibility, none of the parturient were excluded .Therefore for total of 156 parturient, randomization was done into study groups after we received consent from those patient (each group have 52 parturient), and the study was completed.

\section{Results}

\section{Table 1: Demographic Profiles}

\begin{tabular}{|c|c|c|c|c|}
\hline & Group 1 & Group 2 & Group 3 & \\
\hline & $\begin{array}{c}\text { Mean } \pm \text { SD } \\
n=52\end{array}$ & $\begin{array}{c}\text { Mean } \pm \text { SD } \\
n=52\end{array}$ & $\begin{array}{c}\text { Mean } \pm \text { SD } \\
n=52\end{array}$ & p value * \\
\hline Age & $26.54 \pm 3.41$ & $26.92 \pm 4.01$ & $28.06 \pm 4.11$ & 0.116 \\
\hline Height(cm) & $158.12 \pm 3.12$ & $157.45 \pm 3.561$ & $159 \pm 3.94$ & 0.085 \\
\hline Weight( kgs ) & $67.04 \pm 13.08$ & $64.88 \pm 10.11$ & $68.67 \pm 9.91$ & 0.221 \\
\hline
\end{tabular}

$*(\mathrm{n}=52)$ number of patients in each group, Data are represented as mean \pm S.D standard deviation, **statistically insignificant $(\mathrm{P}>0.05)$.

Demographic data such as age,height, weight, ASA status and duration of surgery were comparable between the groups [Table-1].

No statistical significant difference was observed in the onset of sensory block, time to maximal sensory block height and time to complete motor blockade between the groups $(\mathrm{P}>$ 0.05).Regression time to sensory block $\mathrm{T} 10$ was found statistically significant between the groups $(\mathrm{P}=0.002)$.

On intergroup comparisons the regression time to T10 among the groups was significantly higher in Group3 compared to Group2 $(\mathrm{p}=0.002)$. Group1 was comparable to Group2 and Group3 and statistically insignificant.

\section{Table 2: Comparison of Block Characteristics}

\begin{tabular}{|c|c|c|c|c|}
\hline \multirow{2}{*}{ Block characterstic } & Group 1 & Group 2 & Group 3 & \multirow{2}{*}{ p value } \\
\cline { 2 - 4 } & Mean \pm SD & Mean \pm SD & Mean \pm SD & 0.827 \\
\hline $\begin{array}{c}\text { Onset time of sensory } \\
\text { block(sec) }\end{array}$ & $58.29 \pm 27.95$ & $56.02 \pm 16.68$ & $56.06 \pm 18.11$ & 0.808 \\
\hline $\begin{array}{c}\text { Time to maximal sensory } \\
\text { block height(min) }\end{array}$ & $4.22 \pm 1.49$ & $4.13 \pm 1.15$ & $4.05 \pm 1.20$ & 0.443 \\
\hline $\begin{array}{c}\text { Time to complete motor } \\
\text { blockade(min) }\end{array}$ & $2.94 \pm 0.57$ & $2.92 \pm 0.6$ & $2.8 \pm 0.67$ & 0.002 \\
\hline $\begin{array}{c}\text { Regression time to } \\
\text { T10(min) }\end{array}$ & $173.44 \pm 30.77$ & $160.88 \pm 39.1$ & $185.58 \pm 33.53$ & \multirow{2}{*}{} \\
\hline
\end{tabular}

$*(\mathrm{n}=52)$ number of patients in each group, Data are represented as mean \pm S.D (Standard deviation), **Statistically insignificant $(\mathrm{P}>0.05)$

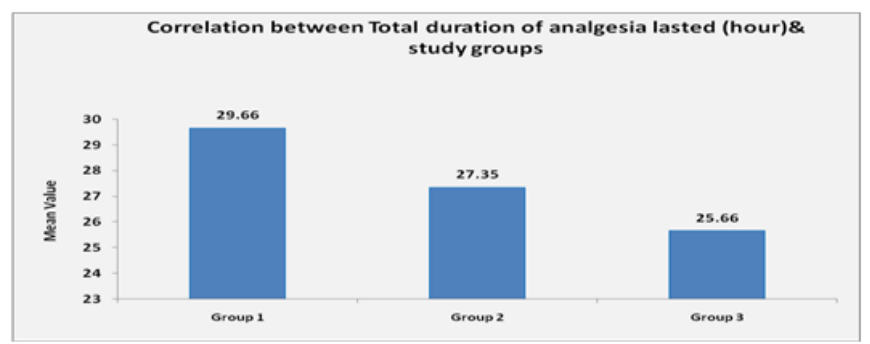

Graph 1: Comparison of Total Duration of Analgesia

The bar diagram show total duration of analgesia is maximum in Group1 (29.66hour) and minimum in Group3 was (25.66hour). However this difference was statistically nonsignificant.

Intraoperative hypotension, bradycardia, pruritis, sedation, respiratory depression, were statistically nonsignificant. Nausea and vomiting was more in Group2 as compared to Group1 and Gruop3. On comparing incidence among the groups statistically nonsignificant difference was observed between premixed and sequential group.

Postoperative hypotension was more in Group2 as compared to Group1. Between the groups statistically significant difference was obsereved ( $\mathrm{p}=0.026$ ). However on comparing among the groups, no statistical significant difference was observed.

Postoperative bradycardia, nausea and vomiting, pruritis, prolonged sedation were statistically nonsignificant between the groups $(p>0.05)$.None of the parturient experienced PDPH and neurologyical deficit in any group.

In all the groups outcome of neonate was analyzed, which came out similar in all the groups, in terms of APGAR scores. Statistically nosignificant difference was obsereved between the groups.

\section{Discussion}

Spinal anaesthesia is a preferred technique for emergency or elective LSCS and enabling early detection of complications. For extending duration of action the IT LA dosage need to be increased. However, it can contribute to significant hemodynamic instability especially in pregnant patients .The mixing of adjuvants to LA interathecally aims to extend LA duration of action and provides post operative analgesia. ${ }^{[10]}$ In our reports that sensory blockade onset was comparable between difference groups. Keera A.A.et al. observed mean 
level of maximal sensory block was nonsignificantly higher in sequential group. ${ }^{[11]}$

We observed mean values of maximum sensory block height was T6 in all the three groups. Cesur M et. al. suggested loss of pin prick sensation at T6 sufficient for continuation of surgery. ${ }^{[12]}$

The onset time of motor block and Bromage 3 were correlated with Hussien RM.et al. who discussed that, there was no significant difference on the onset of motor block between rapid and normal sequential administration of intrathecal fentanyl with hyperbaric bupivacaine $(\mathrm{p}=0.35)$. When fentanyl was injected in a rapid sequential manner, resulted in increased somatic analgesia with no effect on degree or level of motor block, induced by LA. ${ }^{[13]}$

In our study regression time to sensory block T10 was found statistically significant between the groups $(p=.002)$, but on comparison between premixed and sequential group no statistically significant difference was seen. Hussien RM et.al.and Desai $\mathrm{S}$ et al. also reported similar result. ${ }^{[4][13]}$

Resolution time to motor block (Bromage 0) was comparable to each other, and it was statistically insignificant ( $p>0.005)$. Our study correlated with Desai S. et al. and Hussien RM. et al. study who found no difference in regression time to bromage 0 between premixed and sequential groups. ${ }^{[4][13]}$

We observed that in our study, clinically maximum analgesia lasted in premixed group after the surgery followed by sequential groups but statistically it was nonsignificant. However Hussien RM et al. concluded that sequential injection of IT fentanyl when given rapidly, it prolongs postoperative analgesia. ${ }^{[13]}$ Ummenhofer WC.et al. found that morphine injected intrathecally results in adequate and long lasting analgesia due to its hydrophilicity, decreased systemic absorption, cephalad spread in cerebrospinal fluid and slow rate of clearance from the opioid receptors. ${ }^{[14]}$

Hemodynamic parameters (SBP, DBP, MABP) showed no statistically significant difference in all the three groups when compared with base line. Similarly Keera AA.et al. and Hussien RM.et al. found no difference in blood pressure measurements when compared from baseline when heavy bupivacaine was given along with fentanyl in sequential and premixed groups. ${ }^{[11][13]}$

Intraoperative incidence of hypotension, bradycardia, pruritis, sedation, respiratory depression and additional analgesic requirement are comparable in each group.

The incidence of intra-operative nausea and vomiting was statistically significant among the group $(p=0.021)$, but on comparison between premixed and sequential group no statistically significant difference was seen. Hussien RM et.al.and Desai $\mathrm{S}$ et al. also reported similar result. ${ }^{[4][13]}$

Peritoneal traction and exteriorization of the uterus during a cesarean section and predominant vagal effect can lead to nausea and vomiting by triggering the vomiting center. ${ }^{[15]}$

Postoperative hypotension was statistically significant $(p=0.026)$. However on comparing incidence among the groups, no statistical significant was observed $(\mathrm{p}>0.05)$. Kyokong $\mathrm{O}$. et al. first described late hypotension, but mechanism of late hypotension is unidentified. ${ }^{[16]}$

According to keera AA.et al. who described late hypotension mechanism, some patients have moderately weak compensatory mechanism in the upper half of the body which is exhausted after more than $30 \mathrm{~min} .{ }^{[1]}$
Statistical analysis of the APGAR score at $1 \mathrm{~min}, 5 \mathrm{~min}, 10$ min was statistically insignificant ( $\mathrm{P}>0.005)$ among the groups . Our study correlated with Atalay C. et al and Biswas BN. et al. who observed no significant differences in APGAR SCORE among the groups. ${ }^{[17][18]}$

\section{Limitations}

Our study had few limitation.We did not took into consideration the temperature of the drugs and baricity of the drugs used.

\section{Conclusion}

Premixed and sequential administration of IT morphine with hyperbaric bupivacaine were comparable in terms of quality of subarachnoid block maternal hemodynamic and neonatal outcome.

IT morphine when given sequentially and as a mixture with hyperbaric bupivacaine for spinal anaesthesia provides comparable analgesia to mother at rest and during activities up to 24hours. It also clinically prolong the duration of postop analgesia.So that parturient may have early ambulation and return to routine activity, which reduces chances of post op DVT. It also reduced post op analgesic requirements with no serious adverse effect on neonates.

\section{References}

1. Gehling M, Tryba M. Risks and side- effects of intrathecal morphine combined with spinal anaesthesia: a meta- analysis. Anaesthesia. 2009 Jun; 64 (6):643-51.

2. Sivevski A. Spinal Anaesthesia for Cesarean section with reduced dose of intrathecal bupivacaine plus fentanyl. Prilozi 2006; 27: 225-36.

3. Thornton P, Hanumanthaiah D, O'Lear R A, Iohom G. Effects of fentanyl added to a mixture of intrathecal bupivacaine and morphine for spinal anaesthesia in elective caesearean section. Rom J Anaesth Intensive Care 2015; 22: 97-102.

4. Desai S, Lim Y, Tan CH, Sia ATH. A randomised controlled trial of hyperbaric bupivacaine with opioids, injected as either a mixture or sequentially, for spinal anaesthesia for caesarean section. Anaesthesia and Intensive care. 2010 Mar;38(2):280-4.

5. Belzarena SD. Clinical effects of intrathecally administered fentanyl in patients undergoing cesarean section. Anesth Analg 1992; 74: 653-7.

6. Dahl JB, Jeppesen IS, Jørgensen H, Wetterslev J, Møiniche S Intraoperative and postoperative analgesic efficacy and adverse effects of intrathecal opioids in patients undergoing cesarean section with spinal anesthesia; a qualitative and quantitative systematic review of randomized controlled trials. Anesthesiology 1999; 91: 1919-27.

7. Craig D,Carli F,Bromage motor blockade score-a score that has lasted more than a life time.Canadian journal of Anesthesia/ Journal canadien d'anesthesie.2018 jul1;65(7):837-8.

8. Van Tetering AA,Van de Ven J,Fransen AF,Dieleman JP,Van Runnard Heimel PJ,Oei SG.Risk factor of incomplete Apgar Score and umbilical cord blood gas analysis:a reterospective observational study.The journal of maternal-fetal \&Neonatal medicine.2017 Nov 2;30(21):2539-44

9. Thong IS, Jensen MP, Miro J,Tan G. The validity of pain intensity measures: What do the NRS,VAS,VRS and FPS-R measure? Scandinavian Journal of pain.2018 jan26;18(1):99-107.

10. Gaddam M. Comparison of intrathecal clonidine and hyperbaric bupivacaine administered as premixed from or sequentially for cesarean section-A randomized controlled study.IRPMS. 2017 Apriljune $; 3: 2$.

11. Keera AA, Elnabtity AM. Two syringe spinal anesthesia technique for cesarean section: A controlled randomized study of a simple way to achieve more satisfactory block and less hypotension. Anesthesia, essays and researches. 2016 May; 10 (2):312.

12. Cesur M, Alici HA, Erdem AF, Borekci B, Silbir F. Spinal anesthesia 
with sequential administration of plain and hyperbaric bupivacaine provides satisfactory analgesia with hemodynamic stability in cesarean section. International journal of obstetric anesthesia. $2008 \mathrm{Jul}$ 1;17(3):217-22.

13. Hussien RM, Rabie AH. Sequential intrathecal injection of fentanyl and hyperbaric bupivacaine at different rates: does it make a difference? A randomized controlled trial. Korean journal of anesthesiology. 2019 Apr;72(2):150.

14. Ummenhofer WC, Arends RH, Shen DD, Bernards CM. Comparative spinal distribution and clearance kinetics of intrathecally administered morphine, fentanyl, alfentanil, and sufentanil. Anesthesiology: The Journal of the American Society of Anesthesiologists. 2000 Mar 1; 92(3):739-53.

15. Pedersen H, Santos AC, Steinberg ES, Schapiro HM, Harmon TW, Finster M. Incidence of visceral pain during caesarean section: the effect of varying doses of spinal bupivacaine. Anesthesia and analgesia. 1989 Jul;69(1):46-9.

16. Kyokong $\mathrm{O}$, Charuluxananan S, Pothimamaka S, Leerapun $\mathrm{R}$. Hypotension in spinal anesthesia for cesarean section: a comparison of $0.5 \%$ hyperbaric bupivacaine and $5 \%$ hyperbaric lidocaine. Journal of the Medical Association of Thailand= Chotmaihet thangphaet. 2001 Jun; 84: S256-62.

17. Atalay C, Aksoy M, Aksoy AN, Dogan N, Kürsad H. Combining intrathecal bupivacaine and meperidine during caesarean section to prevent spinal anaesthesia-induced hypotension and other side-effects. Journal of International Medical Research. 2010 Oct ; 38(5):1626-36.

18. Biswas BN, Rudra A, Bose BK, Nath S, Chakrabarty S, Bhattacharjee S. Intrathecal fentanyl with hyperbaric bupivacaine improves analgesia during caesarean delivery and in early post-operative period. Indian $\mathbf{J}$ Anaesth. 2002 Dec;46(6):469-72.

Copyright: (C) the author(s), 2020. It is an open-access article distributed under the terms of the Creative Commons Attribution License (CC BY 4.0), which permits authors to retain ownership of the copyright for their content, and allow anyone to download, reuse, reprint, modify, distribute and/or copy the content as long as the original authors and source are cited.

How to cite this article: Jahanara, Koshyari HS, Asthana V Nautiyal R. Comparison of Premixed with Sequential Administration of Intrathecal Morphine and Hyperbaric Bupivacaine for Lower Segment Caesarean Section. Acad. Anesthesiol. Int. 2020;5(1):174-178.

DOI: dx.doi.org/10.21276/aan.2020.5.1.37

Source of Support: Nil, Conflict of Interest: None declared. 